\title{
Pasado y presente de los estudios comparados sobre cine latinoamericano
}

\section{Past and Present of the Comparative Studies on Latin American Cinema}

\author{
Ana Laura Lusnich \\ Universidad de Buenos Aires - Conicet \\ alusnich@gmail.com
}

\begin{abstract}
Resumen
El presente texto propone la comprensión histórica de una de las líneas teóricometodológicas que han signado los estudios sobre cine latinoamericano. Con sus primeros exponentes en la década del 80 , y un creciente énfasis en las posteriores, esta tendencia consolidó una serie de modelos distintivos, que se enriquecieron con el trabajo realizado por investigadores latinoamericanos, y por todo un conjunto de estudiosos que en otros centros académicos mundiales depositaron su interés en nuestras cinematografías. Tomando como marco de referencia los escritos de mayor circulación académica a nivel internacional, el artículo se centrará en el reconocimiento de las distintas fases que marcan la historia de los estudios comparados sobre el cine latinoamericano, así como en la explicación de las principales situaciones y modalidades de comparación que organizan los textos.
\end{abstract}

\section{Palabras clave}

Cine latinoamericano, estudios comparados, situaciones de comparación, modalidades de comparación

\begin{abstract}
This paper proposes a historical understanding of the theoretical and methodological lines that have characterized the studies about the Latin American cinema. With its early exponents in the '80s and an increasing emphasis later, this trend consolidates a number of distinctive patterns, which were enriched by the work done by Latin American researchers, and a group of scholars that in other academic centers put their interest in our cinema. Based on a frame of reference the academic work with the most widely circulated at the international level, this paper focus on the recognition of the different phases that mark the history
\end{abstract}


of comparative studies of Latin American cinema. Moreover, this work analyzes the comparative patters that organize the texts.

\section{Keywords}

Latin American Cinema, Comparative Studies, Comparison Situations, Methods of comparison

1.

Con sus primeras manifestaciones en los años ' 80 y el impulso cualitativo que el historiador Paulo Antonio Paranaguá imprimió al tema en sus publicaciones más recientes, los estudios comparados sobre cine latinoamericano consolidaron a través del tiempo una perspectiva teórico-metodológica en constante crecimiento y desarrollo.

Esta línea de análisis compartió los grandes interrogantes que el comparatismo ${ }^{1}$ estableció en sus orígenes mismos y para otras disciplinas (la historiografía y los estudios literarios, en especial), girando los cuestionamientos en torno a dos problemas en particular: a. ¿es posible estudiar de forma comparada cinematografías que desde el punto de vista histórico y cultural no son equiparables ni homologables sino de forma relativa, y que en lo referido al campo cinematográfico han vivido realidades disímiles en lo que respecta a la producción, distribución y exhibición de los films?; b. ¿cuáles son los alcances y limitaciones de un estudio de esta naturaleza?, ¿es posible diseñar un modelo de estudio comparado sin recurrir a generalizaciones, que contemple las similitudes y los rasgos distintivos de cada cinematografía?. A partir de estas demandas, los textos sobre cine latinoamericano dedicados a explorar y establecer posibles vías o trayectos de análisis de este tipo ${ }^{2}$ formularon diferentes respuestas y estrategias, recobrando con mayor o menor amplitud y conciencia los

\footnotetext{
1 De acuerdo con el uso habitual en otras disciplinas, las nociones "estudios comparados" y "comparatismo" se utilizarán de forma equivalente en este escrito.

2 Este trabajo ha rastreado y recuperado las publicaciones de mayor circulación académica a nivel internacional. Sin embargo, es necesario mencionar tres tesis de doctorado defendidas en los últimos años que tratan temas comparados entre Argentina y Brasil. Estas son: Fabián Núñez: "O que é Nuevo Cine Latinoamericano?. O cinema moderno na América Latina segundo as revistas cinematográficas especializadas latino-americanas", Universidad Federal Fluminense, Niterói, 2009; Silvana Flores: "Regionalismo e integración cinematográfica: el Nuevo Cine Latinoamericano en su dimensión continental (1960-1970)", Universidad de Buenos Aires, Buenos Aires, 2011; Marina Moguillansky: "Pantallas del sur. La integración cinematográfica en el Mercosur", Universidad de Buenos Aires, Buenos Aires, 2011.
} 
objetivos centrales de esta tendencia de estudio: el respeto por las diferencias y el destierro de los reduccionismos. ${ }^{3}$

Con el interés de lograr una comprensión abarcativa de los sucedido en este campo a lo largo del tiempo, este artículo se centra en el reconocimiento de las distintas fases que marcan el derrotero de los estudios comparados sobre el cine latinoamericano, así como en la explicación de las principales situaciones y modalidades de comparación que organizan los textos. Nos interesa señalar en este punto que, en su curso histórico, estos tres aspectos aparecen atravesados o tamizados por las grandes concepciones históricas sobre el cine (la historiografía clásica, los nuevos modelos que desde los años '70 cruzan teoría e historia, la consolidación de los estudios culturales y/o poscoloniales en las últimas décadas ${ }^{4}$ ), situación perceptible en los esquemas temporales, las periodizaciones, el manejo de los documentos, etc. Los años '90 implican, por su parte, la plena asunción de un criterio sobre el cual los historiadores reflexionaron tempranamente y que Chris Lorenz (2005) asocia a la existencia en este método de una "política de la comparación histórica”, que a diferencia de otras tradiciones -las historias nacionales, como ejemplo contrastante-, contiene como cualidades y parámetros interpretativos las relaciones múltiples, las transferencias, la intertextualidad y la concepción plural o pluralista de la Historia.

2.

El primer aspecto que identifica a los textos es la configuración de las situaciones de comparación, pudiéndose distinguir dos alternativas principales que responden a las dimensiones contrapuestas del tiempo histórico tratado. Algunos de ellos (los publicados por Guy Hennebelle y Alfonso Gumucio Dagron, 1981; Paulo Antonio Paranaguá, 1984; Peter Schumann, 1987; John King, 1990) se aferran a la perspectiva diacrónica, proponiendo la escritura de un panorama general del cine latinoamericano que se sostiene en la periodización preestablecida para cinematografías de otros continentes y que abarca las etapas silente, clásicaindustrial y moderna. Otro conjunto de textos, como contrapartida, se restringe a una visión sincrónica, concentrándose en el período de modernización de las estructuras cinematográficas que emerge hacia mediados de la década del 50 y se extiende hasta los años ' 70 inclusive.

\footnotetext{
${ }^{3}$ Mundialmente, el libro de Pierre Sorlin, Cines europeos, sociedades europeas, 1939-1990, es uno de los referentes del comparatismo en el campo del cine. Sorlin se procura identificar las convergencias temporarias entre áreas culturales próximas, aunque ello no implica la idea de identidad europea ni el borramiento de las individualidades nacionales.

4 Para un conocimiento de las principales concepciones históricas sobre el cine ver: Vicente Sánchez-Biosca, "En torno a algunos problemas de historiografía del cine".
} 
En este panorama, la definición de categorías teóricas en torno a esta etapa (Nuevo Cine Latinoamericano en el caso de Alfonso Gumucio Dagron, 1979; Proyecto continental, Zuzana Pick, 1993; Nuevos cines, José Carlos Avellar, 1995; Alberto Elena y Marina Díaz López, 2003; Susana Velleggia, 2009) exhibe el hallazgo de una serie de parámetros cinematográficos y extracinematográficos comunes que agrupan y alinean las cinematografías de América Latina de forma excepcional y, especialmente, la materialización de un alto grado de conciencia en lo que se refiere a la distinción de la mencionada política de la comparación, ya que es en este contexto histórico específico donde es factible identificar patrones de comparación que se desplazan del ámbito de lo internacional (las relaciones e interacciones gestadas en estos años por los países latinoamericanos: encuentros, festivales, declaraciones de interés, etc.) al espacio de lo supranacional (el reconocimiento de problemas cinematográficos comunes y el hallazgo de respuestas consensuadas en torno a la producción, distribución y exhibición de películas).

De todo este conglomerado de textos, es factible mencionar dos estudios que adscriben a las situaciones de comparación mencionadas y que se concentran en gran medida en las cinematografías de Argentina, Brasil y México: el publicado por Paulo Antonio Paranaguá en 1984 (O cinema na América Latina: longe de Deus e perto de Hollywood) y el editado por Tzvi Tal en 2005 (Pantallas y revolución: una visión comparativa del Cine de Liberación y el Cinema Novo). El libro de Paranaguá adquiere un alto grado de originalidad teórica a partir de la presentación y justificación de una tesis general (aquella que abala la existencia de cinematografías centrales y periféricas) y una particular (la que comprende que la historia de la cinematografía regional se sostiene mediante una dinámica de desagregación y recomposición propia de las cinematografías periféricas), siendo las situaciones críticas (la irrupción del sonido en los años '30 y el diseño de modelos alternativos de producción y expresión a mediados de la década del 50, particularmente) las que marcan el pasaje de una etapa a otra y de una situación de desagregación a una de rearticulación. Localizando sus comparaciones en las cinematografías de Argentina, Brasil y México preferentemente (aunque dedicando cierto espacio a otras cinematografías que no alcanzan el estatuto de industria), el estudio anticipa en sus apartados de inicio y cierre - "Presentación" y "Perspectivas"una serie de ideas que tendrán un desarrollo exhaustivo en las publicaciones realizadas posteriormente por el autor en 2000 y 2003 (la negación de la existencia de un cine latinoamericano comprendido como plataforma común de producción, la defensa de los estudios comparados como antídoto del nacionalismo, la necesidad de reevaluar los parámetros de comparación según las coyunturas y necesidades), organizando en el resto del escrito el análisis de los períodos históricos a partir de una metodología común: se exponen los problemas afines a las 
cinematografías de la región en primer término, se confrontan las particularidades de cada una a continuación. Se advierte que los temas referidos al período silente compensan las trayectorias de Brasil, Argentina y México, destacándose en el primer caso la caracterización de los diferentes ciclos regionales y el auge de la producción entre 1908 y 1910, en el segundo la gestación de algunos géneros autóctonos y la localización en José Agustín Ferreyra a la primera figura que rehuye de la copia de modelos narrativos y espectaculares foráneos; en el de México, la emergencia y el desarrollo de un amplio plantel de actores que dotaron expresivamente al cine de esa etapa. Los desarrollos relativos a las segunda y tercera etapa del cine latinoamericano se rigen, en cambio, según los parámetros de la comparación asimétrica y, paradójicamente, se dedica un mayor espacio a la cinematografía argentina, y aún a la mexicana, para explicar la revolución tecnológica del sonido (Paranaguá expone las razones por las cuales Argentina aprovecha productivamente la transición al sonoro, transformándolo en un vehículo de expresión y de posicionamiento del cine dentro y fuera del país). Lo mismo sucede respecto de la renovación concretada desde mediados de los años ' 50 . En este segmento revisa las diferentes líneas expresivas que se consolidan en Argentina, que incluyen la Generación del sesenta, el cine político-militante y el cine underground de fines de los años ' 60 y principios de los 70, señalando para la cinematografía brasileña, de forma exclusiva, las propuestas de Glauber Rocha en sus planos teórico y práctico.

Tzvi Tal realiza un estudio sincrónico, acotado en el plano temporal a las décadas de 1960 y 1970, en el geográfico a las cinematografías de Argentina y Brasil, y en el estético-ideológico al cine político-militante; de forma excluyente se centra en el Cinema Novo (Brasil) y en las realizaciones del grupo Cine Liberación y de una serie de films próximos de otros colectivos y directores (Argentina). Esta diferencia en el diseño de la línea temporal no distancia al autor de uno de los presupuestos centrales esgrimidos por Paranaguá: la reconsideración de la existencia de un proyecto continental que agrupe e incluya a los países latinoamericanos en esa etapa. La negación de dicha existencia era explicada por Paranaguá a partir de razones asociadas a la ausencia de un aparato productivo y distributivo común -o al menos semejante- que implicara el desarrollo permanente y sostenido del cine en la región; Tal esboza en cambio un esquema argumentativo basado en la conformación de prácticas de resistencia a la colonización cultural y a la opresión neocolonial, que pese al esfuerzo no lograron definir o elaborar un modelo narrativo-espectacular alternativo ni modificaron las estructuras cinematográficas en general. Asimismo, cuestionando a algunos autores contemporáneos (Ana López y Zuzana Pick), discute el carácter eurocéntrico de las nociones que fomentan la imagen de un proyecto continental a partir de la cual, frente a los modelos centrales de Estados Unidos y Europa, "el cine periférico adopta, o los resiste, o los negocia” (Tal, 2005: 73). La opción por una historia que resalte la diversidad cultural y los 
conflictos específicos en los cuales se desarrolla la actividad cinematográfica se presenta entonces como base de la comparación, hallándose tres patrones comunes entre las tendencias estudiadas (la proximidad geográfica, el origen temporal relativamente simultáneo y las intenciones de cuestionar y desestabilizar el estado de cosas) y una cantidad importante de diferencias que, en síntesis, confrontan el ejercicio individual y autoral de la profesión (Brasil) con una práctica colectiva que se desempeña al margen de la Institución cinematográfica (Argentina), y una representación alegórica de las coyunturas políticas y sociales, centrada en un espacio rural de alto contenido metafórico (Brasil), con un modelo realista-crítico que localizaba sus historias en ámbitos urbanos o rurales que poseían un alto grado de referencialidad y una conexión directa con la historia de la lucha obrera (Argentina).

3.

Más allá de la definición dicotómica de las situaciones de comparación, que encuentran en la larga, mediana o corta duración sus esquemas temporales, y de las ideas acerca de la unidad latinoamericana en el campo del cine según tres presupuestos ideológicos que incluyen la creencia en la identidad continental, la convicción de la inexistencia de dicha filiación, o bien la opción intermedia que proclama puntos de integración que no implican la homologación radical de la producción de los países, ${ }^{5}$ los textos estudiados para esta ocasión pueden clasificarse de acuerdo con los parámetros comparativos adoptados.

Según el grado de simetría, transferencia y empleo de las prácticas intertextuales, ${ }^{6}$ reconocemos cuatro modalidades. Las dos primeras señalan las características que signan la fase inicial de los estudios comparados sobre América Latina; las dos restantes inauguran y componen su segundo momento. Es de hacer notar que estas fases no se definen estrictamente de forma cronológica, ya que las dos variantes iniciales han perdurado en algunas de las publicaciones recientes. Por su parte, tempranamente, algunos autores reconocieron la complejidad de los estudios comparados y expresaron una voluntad reflexiva y crítica a la hora del diseño téorico-metodológico: Paulo Antonio Paranaguá funciona en el desarrollo de estos estudios como figura vertebradora de estas distintas modalidades y como principal promotor. Más allá de estas consideraciones, como adelantamos en la presentación de este trabajo, sí es factible encontrar lazos entre las modalidades de

\footnotetext{
5 Zuzana Pick (1993) comparte el primero de estos presupuestos; los libros de Paulo Antonio Paranagúa (1984) y Tzvi Tal (2005) anteriormente tratados son representativos de la segunda opción; la publicación de Paranaguá de 2003, Tradición y modernidad en el cine de América Latina, articula la tercera posibilidad.

${ }^{6}$ En este contexto, las nociones de simetría, transferencia e intertextualidad contemplan el equilibrio o el tratamiento proporcional de dos o más cinematografías así como la capacidad de relacionarlas.
} 
comparación y los paradigmas históriográficos más relevantes, de forma tal que en la primera fase caracterizada se manifiesta un real interés por construir relatos homogenizadores y en los cuales la periodización -larga o estrecha- del tiempo histórico era una característica escritural central. Con el paso del tiempo, en el curso de la segunda fase y en consonancia con la concepciones renovadoras sobre el cine que desde los años '70 implicaron una fecunda renovación, aparecieron otras prioridades entre las que se destacan la mayor intervención teórica y metodológica en el diseño de las investigaciones y una mayor exhaustividad en el hallazgo y manejo de las fuentes.

\subsection{Primera fase: la Historiografía paralela y la combinación de la Historiografía paralela y la Comparación asimétrica:}

El patrón de la "Historiografía paralela" se actualiza en mayor o menor medida en las publicaciones de Alfonso Gumucio Dagron, 1979; Guy Hennebelle y Alfonso Gumucio Dagron, 1981; Julianne Burton, 1986; Michel Martin, 1997; Alberto Elena y Marina Díaz López, 1999; Elena y Díaz López, 2003; Paulo Antonio Paranaguá, 2003; Susana Velleggia, 2009, y Paranaguá, 2009. Se trata de obras que restringen la situación de comparación a la introducción para luego organizar los datos y el desarrollo de los temas en el marco de contextos nacionales. De esta manera, la comparación no es construida dentro del diseño de investigación propiamente dicho, reservándose la enunciación de los rasgos internacionales o supranacionales a los capítulos de presentación.

Esta elección aparece certeramente motivada en los textos que compilan trabajos o documentos de diversos autores, o que incluso pertenecen a distintas nacionalidades (Hennebelle y Gumucio Dagron; Burton; Martin; Elena y Díaz López; Velleggia; los dos volúmenes sobre cine documental editados por Paranaguá ${ }^{7}$ ), pero es factible de ser debatida en otros casos, como el de Alfonso

\footnotetext{
7 Susana Velleggia desarrolla en cuatro extensos capítulos los puntos de unión del cine de intervención política en América Latina, repasando los conceptos en juego en los distintos países. Luego, una segunda parte de su trabajo, se organiza en base a la selección de documentos del cine político latinoamericano producidos entre 1967 y 1977 . Entre estos, dos apartados se dedican al cine argentino y brasileño (otros a las cinematografías de Bolivia, Cuba, Chile, Colombia, Cuba, El Salvador y México), especialmente a los ensayos y reflexiones que marcan el cine político de los años '60 y las transformaciones que este ha sostenido en la década posterior. Por su parte, Alberto Elena y Marina Díaz López califican al libro por ambos editado en 2003 como una antología del cine latinoamericano, que sin ser la primera en su clase, se distingue por ofrecer una síntesis de su desarrollo, proveyendo información relevante y también algunas claves necesarias para su interpretación. Con la intención de balancear el estudio de films de distintos países, períodos y tendencias, los editores optan por una selección de títulos realizados desde el período sonoro hasta comenzado el siglo XXI. Presupuestos equivalentes son los que organizan las dos publicaciones de Paulo Antonio Paranaguá sobre cine documental, incluyéndose además de análisis de los documentales representativos de la región, reflexiones que han marcado el desarrollo de estas prácticas.
} 
Gumucio Dagron, en cuyo estudio titulado Cine, censura y exilio en América Latina, se analiza la desarticulación del Nuevo Cine Latinoamericano en el contexto del ascenso de gobiernos autoritarios y a partir de tres ejes en particular: la censura, la autocensura y el exilio. En lo referido al recorte temporal del objeto de estudio, la investigación se caracteriza por un eclecticismo manifiesto: en los casos de Bolivia y Colombia el autor se retrotrae a las décadas del 30 y 40 mientras que en los otros segmentos nacionales se restringe a las del 60 y 70. A su vez, el dispar manejo de las mencionadas nociones de censura, autocensura y exilio torna compleja la lectura, ya que si en un primer tramo se intenta clasificar las formas de censura según su origen (estatal, sindical, interna a la institución cinematográfica, la ejercida por la crítica), en otros se modifica el eje de comprensión, equiparando la idea de proteccionismo estatal con la de censura velada y condicionante. La fecha de escritura del texto, especialmente de su primera versión, marcada por el exilio, la fragmentación y la ausencia de una parte de las fuentes primarias y secundarias, y el carácter de denuncia, funcionan en este sentido como aspectos claves que pautan el estilo escritural de la obra y, en primer lugar, sus objetivos inmediatos.

En el primer capítulo, dedicado al cine argentino, el autor describe cinco prácticas que incidieron en el desmantelamiento del cine político; por su grado de coersión sobre los sujetos son ordenadas de la siguiente manera: autocensura, censura, persecución, exilio y asesinato. Resulta de mayor interés el debate que inicia al oponer -quizás atraído por las reflexiones contemporáneas de Cine Liberación acerca del primer, segundo y tercer cine- tres tipos de cine que hicieron eclosión en los años '60: el "falso nuevo cine" (representado por Torre Nilsson), el "verdadero nuevo cine" (el cine de expresión nacional que se realizaba al margen de la industria: Martínez Suárez, Dawi, Feldman, Kohn, Kuhn, Alventosa, Antín) y el "verdadero cine nacional" (Birri): "el cine que al basarse sin tapujos en la realidad argentina provocaría la reacción del aparato censor” (Dagron, 1982: 19). A continuación, el segmento dedicado a Bolivia se articula en función de la hipótesis que afirma que el cine boliviano nació y se desarrolló con la censura encima, situación que marcó el estreno del primer largometraje (La profecía del lago, de José María Velasco Maidana), para retornar cíclicamente a lo largo de su historia. El capítulo sobre Brasil explica los avatares históricos que determinaron el derrotero del Cinema Novo y los cambios expresivos motivados por distintas formas de censura desde 1955, año en que Río cuarenta grados de Nelson Pereira dos Santos fue víctima de la persecución. Gumucio Dagron destaca la autocensura adoptada por algunos directores frente a la prohibición de Barravento de Glauber Rocha por el gobierno progresista de Goulart; la censura ejercida por el Centro Popular de Cultura, institución que propiciaba la discusión de los proyectos antes de ser estrenados, y donde distintos sectores de derecha e izquierda atacaron duramente la ópera prima de Carlos Diegues, Ganga zumba; la creciente censura de la primera etapa de la 
dictadura militar de los años 1964-1968, diversificada con las prácticas de las confiscaciones de films, la alteración del montaje de algunos de ellos, las amenazas a los directores, el exilio, el repligue y la sumisión de aquellos que permanecieron en el país. Acompañando esta fase, una forma de autocensura señalada por el autor se asocia a la mutación formal de los films, quienes se refugian en construcciones alegóricas que, si bien burlan a la censura, alejan al público, que no logra percibir por detrás de esas estructuras el mensaje social. Por su parte, el segmento relativo al cine chileno se entronca con la idea vertida para el caso boliviano, que si en aquella ocasión hablaba de la situación estructural del arte cinematográfico, determinado y acorralado por la censura desde los orígenes mismos del medio, en el contexto de Chile refiere al asesinato del cine, en tiempo presente (desde 1973 en adelante, luego de la toma del poder por parte de los militares) y de forma absoluta.

La combinación de la "Historiografía paralela" y la "Comparación asimétrica", que por distintos factores (carencia de fuentes, conocimiento mayor de una cinematografía, intereses distintivos), destaca una cinematografía por sobre otras, estructura metodológicamente los libros de Paulo Antonio Paranaguá (1984) y John King, (1990), constituyéndose como segunda modalidad de comparación. Si las asimetrías vigentes en el texto de Paranagúa puntualizadas con anterioridad en este trabajo pueden ser aceptadas en base a la necesidad que manifiesta el autor de ajustar sus ejes transversales de comparación según las sucesivas etapas de la historia del cine latinoamericano, situación que implica el desplazamiento del foco de atención de un país a otro según las ocasiones, en la obra de John King, El carrete mágico. Una historia del cine latinoamericano, reproducen en el ámbito del continente la oposición entre cinematografías centrales y marginales. En su introducción, el autor justifica la atención prestada en los dos primeros capítulos a las cinematografías silentes y clásica-industrial de Argentina, Brasil y México en detrimento de las restantes, esbozando los argumentos de la ausencia de copias de los otros países de la región y del rango distintivo de esta trilogía en el mapa continental. Respecto de la segunda parte del libro, abocada a los años que van de 1960 a 1980 y cuyos films son catalogados bajo la denominación de Nuevos Cines, la estructura se reproduce, ya sin fundamentación alguna, dedicándose amplios capítulos a estos países (a los que se suma Cuba por el peso de la producción en torno a la Revolución Cubana), y acotándose los referidos a otras cinematografías de América Latina. En una u otra oportunidad, se deja en claro el peso sustancial o relativo de los países, que no parece variar en la diacronía histórica, legitimándose con estos presupuestos la hegemonía de algunas sobre otras. Por ejemplo, no se explora los motivos por los cuales México, en los años ' 60 y '70, no coparticipa en los procesos de modernización; como contrapartida, a cinematografías activas en este período (Chile, Bolivia, Ecuador, Colombia, Perú) se les niega dicha particularidad, relegándolas al bloque de países subsidiarios o periféricos del 
continente. Sobre los análisis del cine brasileño, particularmente, sucede una contradicción, ya que se lo presenta a partir de la categoría de "cine industrial", o produciendo fenómenos similares a los concretados en Hollywood (el Sistema de estrellas y el Sistema de géneros). Luego, en segmentos posteriores, se niegan o relativizan estos procesos; en diálogo evidente con las investigaciones realizadas por otros autores, en breves siete páginas, se sostienen unas pocas ideas respecto de estas etapas del cine brasileño: una es la vinculada al dominio del medio cinematográfico, en las primeras dos décadas, por parte de los sectores aristocráticos de la población, otra propulsa la emergencia de los ciclos regionales, aunque no se incorporan en estos tramos problemas capitales asociados a la posibilidad de percibir en estos las tensiones trazadas entre términos dicotómicos: modernismo/regionalismo, campo/ciudad, civilización/barbarie. El capítulo en torno a los años ' 60 y ' 70 incurre asimismo en un reduccionismo, ya que sólo trata el movimiento cinemanovista a la luz de los cambios políticos. El estudio del caso argentino se encuentra plagado de disrupciones, de hecho sólo se mencionan algunos ejemplos del cine silente, para afiliarse el autor a continuación -citando letras de tango, algunas escenas de los films silentes de Ferreyra y un pintoresco aunque arbitrario relato hecho por un extranjero a quien al llegar al Río de la Plata le ofrecen los servicios de un cinematógrafo/burdel-, a una perspectiva que ha sido tradicionalmente registrada por algunos intelectuales, periódicos y revistas nacionales de corte conservador: la necesidad de crear la regulación estatal para el sector. En la segunda parte, el análisis sobre el cine argentino se amplifica, aunque los parámetros no son renovadores: se listan los aportes de la nueva ola de directores en los años '60 (Torre Nilsson, Ayala), se explican el realismo crítico de Birri y la resistencia materializada por Cine Liberación, extendiéndose el capítulo a un conjunto estrecho y errático de films y directores hasta el momento de la recuperación de la democracia en $1983 .^{8}$

\subsection{Segunda fase: Desplazamiento de la interpretación paralela de los hechos histórico-políticos y de las tendencias cinematográficas, y Propuesta de ejes transversales de comparación:}

Iniciando una segunda fase de los estudios comparados sobre el cine de América Latina, otro conjunto de textos pone en práctica una vía teóricometodológica alternativa que, vinculada a la coyuntura histórica que desde los años sesenta implicó la desarticulación del Estado-Nación como foco central de los

\footnotetext{
${ }^{8}$ La asimetría, rasgo central de este esquema de comparación, aparece interceptada y contaminada por la ausencia del documento fílmico en sentido estricto. Esta característica, constitutiva de la historiografía clásica del cine, implica para Vicente Sánchez-Biosca (1998) el reemplazo del foco de atención de las fuentes primarias por la memoria -no siempre satisfactoria- del cronista o historiador.
} 
modelos historiográficos, ${ }^{9}$ materializa el ascenso de otros aspectos como centro de la discusión, los que aparecen en primer plano o estableciendo un diálogo entre sí: lo social, lo étnico, lo regional, lo genérico, las identidades múltiples. En estos casos la fragmentación y la multiplicación reemplazan las nociones de unidad y organicidad perseguidas por la comparatística tradicional y el interés puesto en el plano político. En lo referido a nuestro campo de estudio, desplazan preconceptos arraigados a lo largo del tiempo que implicaban una interpretación paralela de los hechos histórico-políticos y de las tendencias cinematográficas, de forma que se destacaba el condicionamiento de la primera esfera sobre la segunda, o bien se fundamentaba la manera en que el cine anticipaba o condensaba, necesariamente, las claves reinantes en la serie política. Este desentendimiento favoreció asimismo la puesta en primer plano de la teoría, o al menos la asimilación entre la historia y la teoría, y una singular apertura y cruce entre los estudios de cine y otros campos del pensamiento contemporáneo.

Una de las primeras investigaciones que adhieren a esta modalidad de comparación la proveyó en 1993 Zuzana Pick en su publicación The New Latin American Cinema. A Continental Project, que se enmarca en la producción que la academia norteamericana inicia en las últimas décadas y que, en líneas generales, abarca los estudios culturales y poscoloniales. Su recorte temático y fílmico se corresponde con la tesis de la conformación de un proyecto cinematográfico continental, que la autora reconoce a partir de tres aspectos claves (la modernización del lenguaje cinematográfico, la constitución de modos de producción y circulación novedosos y la radicalización y el cambio de perspectivas ideológicas) y periodiza en cuatro fases: a) manifestaciones tempranas del Nuevo Cine Latinoamericano (años '50), b) período de nacimiento y desarrollo (19601967), c) etapa de solidificación (1970-1976), y d) fase de consolidación e institucionalización (años '80, posteriores a la recuperación de los gobiernos democráticos). Ahora bien, si la presentación del problema de investigación se realiza en la "Introducción" y el capítulo inicial titulado "Convergencias y divergencias", los cinco restantes se estructuran en base a áreas transversales e innovadoras de comparación (Creatividad e intervención social, Identidades de género y feminidad; Memoria popular y poder de clase; Diferencias culturales y

\footnotetext{
9 Cronológicamente, el auge y la difusión de este método comparado se localiza en el contexto posterior a los años '60, de forma que "la crisis del Estado-Nación es equiparable con la crisis de la historiografía tradicional" (Lorenz, 2005: 37). La fragmentación y la desintegración de lo que habitualmente se concebía unificado o formando un todo (la conciencia histórica de la Nación, el Estado-Nación que se distingue por razones políticas, geográficas, raciales y/o religiosas), es uno de los factores que intervino en el desarrollo de perspectivas comparadas y en el progresivo reemplazo de aquellas que acotaban los estudios a casos nacionales (ya sea con un espíritu acabadamente nacionalista o crítico).
} 
representaciones; Exilio y desplazamiento), ${ }^{10}$ y mediante el análisis de films paradigmáticos, que abarcan siete cinematografías: de Argentina se analizan cuatro films (Los inundados, La hora de los hornos, Camila y Tangos: el exilio de Gardel), de Brasil otros cuatro títulos (Los fusiles, Iracema, Quilombo y Gaijin: el camino de la libertad), de Cuba y Chile se retoman tres ejemplos de cada país, de Colombia, Bolivia y México se estudia un film de cada uno. Argentina interviene en cuatro capítulos, con excepción del referido a las diferencias culturales y étnicas y sus representaciones; Brasil participa en dos de ellos, los que tratan los temas de la memoria popular y el poder de clase, y particularmente en el dedicado a las diferencias culturales y raciales, en cuyo segmento se estudian tres películas brasileñas con el interés de explicar la manera en que el cine latinoamericano de esas décadas se esforzó por integrar la etnicidad dentro de las políticas audiovisuales de representación: "las películas analizadas en este capítulo, a pesar de sus deficiencias, representan la lucha esbozada para llegar a un acuerdo con las mitologías del mestizaje y la posibilidad de rearticulación de los grandes relatos de la identidad nacional" (Pick, 1993: 130, traducción propia). ${ }^{11}$

Finalmente, trazando puntos de continuidad con la modalidad anterior, es posible reconocer estudios que sostienen un "Sistema de relevancia específico", que no sólo aclara los rangos de contraste que se constituirán en la base teóricometodológica de la investigación sino que también delimita y precisa la situación de comparación. Ambos aspectos dejan en claro que la información factual interesa sólo en la medida en que es de significación para preocupaciones presentes y de

\footnotetext{
10 La autora sintetiza con estas palabras los parámetros adoptados en su estudio: "He trazado seis áreas de investigación para estudiar la compleja interrelación entre los objetivos supranacionales del Nuevo Cine Americano y las tendencias nacionales que han contribuido a dar forma a la ideología del movimiento" (Pick, 1993: 4, traducción propia). Se propone tratar algunos de los problemas referidos a la construcción de una identidad cinematográfica y cultural que se desplaza del campo de lo nacional a lo regional, así como las posibles vías de articulación entre las partes implicadas y otros universos culturales externos.

11 Un estudio que, centrado en las prácticas documentales, manifiesta intereses similares que se abren a nuevos y transversales problemas, lo constituye el editado en 2009 por Miriam Haddu y Joanna Page, Visual synergies in fiction and documentary film from Latin America. El libro comprende dos capítulos introductorios escritos por Joanna Page y Michael Chanan, en los cuales se presentan los debates que en las últimas décadas se han detenido en teorizar sobre las similitudes y las diferencias entre los films ficcionales y documentales, depositando el interés en aquellas reflexiones que en la actualidad cuestionan las relaciones (complejas, controversiales) que establecen los signos audiovisuales con su referente. Luego, el texto compila artículos de otros autores a partir de cuatro ejes de discusión específicos: a) la hibridación de las técnicas documentales y ficcionales en el cine cubano, argentino y brasileño de corte político-militante en los años '60 y '70, b) la emergencia de representaciones que materializan en el campo del cine los procesos de la migración, el exilio y la multiculturalidad; c) la consolidación del documental performativo y reflexivo en las últimas décadas; y d) la referencia a los debates teóricos y críticos contemporáneos concernientes a los regímenes cinematográficos de significación y a la construcción material y discursiva de la imagen.
} 
cierto grupo de personas. He aquí que: "los desarrollos historiográficos tienen que ser analizados en relación con el horizonte de expectativas del público a quien se dirige" (Lorenz, 2005: 41). De acuerdo con el relevamiento realizado, reconocemos formando parte de esta modalidad los estudios de Silvia Oroz (1992); Paulo Antonio Paranaguá (2003); Christian León (2005); Adrián Pérez Llahí (2005) y Cacilda Rego y Carolina Rocha (2011), especialmente. ${ }^{12}$

La propuesta de Paranaguá de 2003, titulada Tradición y modernidad en el cine de América Latina, retoma de sus publicaciones anteriores el afán por la reflexión acerca de los límites y alcances de los estudios comparados en el campo del cine latinoamericano y se constituye en uno de los ejemplos representativos de esta modalidad. Las hipótesis de la inexistencia del cine latinoamericano comprendido como una unidad de producción, consumo y distribución, y la que caracteriza a estas cinematografías como dependientes -pronunciadas ambas en su publicación del año 2000-, no impiden al autor propiciar estudios comparados. Estos comienzan a orientarse al reconocimiento de las similitudes y diferencias entre las cinematografías, mediante patrones de comparación precisos, acordes a contextos históricos específicos y a preocupaciones puntuales. En este caso, quince nociones articuladoras que tienden a explicar o problematizar las tensiones existentes entre los términos tradición/modernidad, y nacionalismo/cosmopolitismo. Si nos referimos a la intervención de las cinematografías brasileña y argentina, el capítulo titulado "Neorrealismo" hace foco en un conjunto de films brasileños, preferentemente, y en un puñado de títulos argentinos, cubanos y mexicanos, a partir de los cuales Paranaguá identifica una corriente interna (híbrida en sus formas, alternativa en la gestación de un modo de producción y en la elección de nuevas estrategias comerciales) que opera en una escala y un tiempo amplio con epicentro en el período de transición del modelo clásico-industrial al cine moderno, fecha en la que producen obras Nelson Pereira dos Santos y Fernando Birri, entre otros. El capítulo "Populismo", por su parte, entabla la transposición de la obra teatral del brasileño Joracy Camargo, titulada Deus the pague, al cine argentino, en la versión realizada por Luis César Amadori en 1948. Teniéndose en cuenta las

12 Dentro de esta modalidad también es posible inscribir una serie de escritos, todos ellos publicados en el volumen Teorías y prácticas audiovisuales. Actas del primer Congreso Internacional de la Asociación Argentina de Estudios de Cine y Audiovisual publicado en Buenos Aires, editorial Teseo, 2010. Estos ensayos se compendian en un apartado del libro, titulado "Estudios comparados de Brasil y Argentina". Fueron escritos por Luciano Barandiaran y Juan Padrón (su tema es el rol de la censura en Argentina y Brasil entre 1964 y 1983), Silvana Flores (examina los congresos y festivales que se sucedieron en los años '60 y '70), Miriam Garate (analiza las funciones del cine en los primeros tiempos, su participación en la vida social y cultural y su rol como complemento de la literatura), Marina Moguilansky (se ocupa de la política y las acciones para el sector en el marco del Mercosur) y Marina Telesco (analiza la representación de las ciudades latinoamericanas en tiempos de crisis política y económica a partir de los films Tierra extranjera, Walter Salles, 1995, y Mundo grúa, Pablo Trapero, 1999). 
relaciones textuales trazadas entre ambas obras y la circulación del film argentino en nuestro país, Brasil y España, Paranaguá se dedica a enfatizar la idea de que, pese al salto textual operado desde el modelo del teatro varguista al melodrama peronista de Amadori y Argentina Sono Film (la casa productora), "se logran reconciliar los valores conservadores y populistas, la religión y la tensión clasista, la pulsión nacionalista y la experiencia cosmopolita, la tradición y la modernidad, en una hibridación característica de la modernización conservadora que ha prevalecido en América latina" (2003, 157). Otro título emblemático que adscribe a esta modalidad, Melodrama. El cine de lágrimas de América Latina, publicado por Silvia Oroz, define el sistema de relevancia que orienta el estudio al enunciar la idea de la centralidad cultural del melodrama en el paisaje audiovisual latinoamericano del período 1930-1950, explicando que se trata del género más representativo de la industria y de alto alcance popular. En diálogo con las ideas trazadas por Paranaguá, amplía la noción de comparatismo hacia dos direcciones: estudia el melodrama cinematográfico a partir de las formas que presentó en otras disciplinas artísticas (teatro, folletín, radionovela), para luego analizar a partir de un corpus de ciento veinte films latinoamericanos los aspectos expresivos y culturales que se articulan en este género: a. las estructuras narrativas y el sistema de personajes, a partir de los cuales es posible reconocer subgéneros; $b$. las formas y funciones del melodrama en el contexto de la cultura popular; y c. los alcances del género melodramático en la consolidación de las industrias cinematográficas de América Latina. De acuerdo con la mayor a menor cantidad de films estrenados en este período, Oroz retoma en su análisis las realizaciones mexicanas, las argentinas, las coproducciones concretadas entre Cuba y México y los films brasileños. ${ }^{13}$

4.

Los interrogantes mencionados en la apertura de este trabajo acerca de la posibilidad de estudiar de forma comparada cinematografías cercanas en el plano

\footnotetext{
13 Cacilda Rego y Carolina Rocha, editoras de New Trends in Argentine and Brazilian Cinema, dedicadan el libro a las relaciones trazadas entre las cinematografías de Argentina y Brasil. Por sus características escriturales y los objetos de investigación, mantiene vínculos estrechos con otros de similares características, los publicados en 2007 por Denise da Mota da Silva, Vizinhos Distantes: Circulação cinematográfica no Mercosul (el libro examina las determinaciones culturales, políticas, históricas y económicas que caracterizan las cinematografías contemporáneas de Argentina, Brasil, Paraguay y Uruguay), y la compilación efectuada por Gastón Lillo y Walter Moser, titulada Cine, historia y sociedad: Cine argentino y brasileño desde los años 80. En el caso de Rego y Rocha, la selección de artículos de diversos autores se concentra en la producción posterior a 1995 en ambos países, a partir del trazado de un sistema de relevancia que comprende tres ejes de comparación vinculantes: a) las tensiones generadas entre las fases de producción y distribución de films en Argentina, en Brasil y entre ambos países; b) la distinción y el análisis de un conjunto de films en los que se materializa el impacto de las políticas neoliberales sucedidas durante los gobiernos de Fernando Collor de Melo y Carlos Menem y c) el incremento en la actividad de las mujeres y el impacto de la feminidad en la realización de películas.
} 
espacial aunque sensiblemente dispares en lo que respecta al desarrollo de su historia, encuentran en el recorrido trazado respuestas viables y certeras.

De acuerdo con las situaciones de comparación y la delimitación del tiempo histórico, es posible reconocer la existencia de una amplia gama de géneros o tipos de escritos que incluyen las historias generales, las antologías, las historias parciales acotadas a un período, y los ensayos que se ajustan al estudio de una tendencia, un problema de investigación o una coyuntura estética o tecnológica específica. Sobre los presupuestos que incidieron en la definición de la identidad cinematográfica, las oscilaciones manifiestas en ese campo (el hallazgo de numerosos o acotados puntos de encuentro, o la versión diametralmente opuesta que sostiene la ausencia de toda filiación), no impidieron la constitución de los estudios comparados, delineándose en cada caso, en algunos con mayor dedicación que en otros, el escenario internacional o supranacional de investigación.

Respecto de las modalidades de comparación, se procuró agrupar los textos e identificar cuáles han sido hasta el momento los diseños recurrentes de comparación y las actitudes teóricas y metodológicas que los caracterizan. Así, surgieron cuatro modelos que, de acuerdo con la participación y el diálogo originado entre los casos nacionales (cinematografías, directores, películas) abarcan la comparación paralela, la comparación asimétrica, la apertura a ejes transversales y novedosos de comparación, y la paulatina reflexión sobre la necesidad de fijar patrones específicos y articulados de análisis. La revisión de algunos de los trabajos (los dos volúmenes editados por Michel Martin en 1997, por ejemplo) indicó que es incluso factible conciliar modalidades o perspectivas disímiles sin que ello signifique el abandono de la coherencia de los argumentos expuestos en los niveles macro y microestructural. ${ }^{14}$ Otra observación de interés reside en la inclusión, en varios de los textos, ya sea como apéndice o en diálogo con las hipótesis centrales, de ensayos escritos por cineastas latinoamericanos que en una proporción considerable plantean en sí mismos una dimensión comparada de la producción regional, con especial atención en los factores políticos, sociales y culturales que en

\footnotetext{
14 Nos referimos a New Latin American Cinema. Volume 1. Theories, practices and transcontinental articulations y a New Latin American Cinema. Volume II. Studies of national cinema. El primero se encarga de conceptualizar la noción de Nuevo Cine Latinoamericano, el volumen dos se dedica a estudiar las expresiones de este cine en cada país de manera separada (México, Cuba, Puerto Rico, Brasil, Chile, Argentina). En el caso de Nicaragua y El Salvador, por un lado, y de Bolivia, Ecuador y Perú se trabajan en un mismo capítulo por considerarse cinematografías aledañas, En el segundo tomo, además, se abarcan diferentes períodos históricos (algunos artículos se concentran en los años '60, otros se acercan a los 90). Los artículos están escritos por historiadores de diferentes nacionalidades, tanto latinoamericanos como de Estados Unidos, entre ellos Julienne Burton, Paulo Antonio Paranaguá, Zuzana Pick, John King, Robert Stam, Ana López e Ismail Xavier.
} 
las décadas del 60 y 70 reunieron de forma singular a las cinematografías de América del Sur. $^{15}$

Finalmente es necesario mencionar que, asimilando las novedades que las concepciones históricas sobre el cine aportaron en las últimas décadas (el desinterés por la acumulación de hechos y datos, el uso y el análisis exhaustivo de las fuentes, y el diseño y la justificación del andamiaje teórico son aspectos que Vicente SánchezBiosca y Francesco Casetti coinciden en destacar desde los años '70 en adelante), los estudios comparados sobre cine latinoamericano asumieron de forma creciente un mayor grado de reflexividad acerca del método y la exposición de los rangos de contraste. De esta manera, los tradicionales planteos que Marc Bloch enunció tempranamente para el campo de la disciplina histórica, en una serie de premisas básicas aunque decisivas (la identificación de semejanzas y diferencias, o de relaciones y regularidades, que no sometan a los términos comparados a una homologación reduccionista), hallan en los desarrollos contemporáneos de este método en el campo del cine un terreno fecundo y promisorio.

\section{Referencias bibliográficas}

Avellar, J. C. (1995). Aponte clandestina: Birri, Glauber, Solanas, Getino, García Espinosa, Sanjinés, Alea - teorias de cinema na América Latina. Rio de Janeiro/São Paulo: 34/Edusp.

Bloch, M. (1928). "Pour une histoire comparee des societes europeennes". Revue de Synthese. No XLVI.

Burton, J. (1986). Cinema and social change in Latin America: conversation with filmmakers. Texas: University of Texas Press.

Casetti, F. (2004).“La historia, las historias y la historiografía”. En Teorías del cine. Madrid: Cátedra.

Da Mota da Silva, D. (2007). Vizinhos Distantes: Circulação cinematográfica no Mercosul. Sao Paulo: Annablume.

Elena, A. y Díaz López, M. (Eds.). (1999). Tierra en trance. El cine latinoamericano en 100 películas. Madrid: Alianza.

- (Eds.) (2003). (The cinema of Latin America. London: Wallflower Press.

Gumucio Dagron, A. (1984). Cine, censura y exilio en América Latina. México-Bolivia: Film Historia.

15 Las reflexiones de los cineastas (Glauber Rocha, Fernando Birri, Fernando Solanas, Octavio Getino, Jorge Sanjinés, entre otros) han forjado una historiografía propia sobre el cine latinoamericano, alcanzando circulación mundial mediante la edición de libros y ensayos, bien de artículos y entrevistas publicadas en revistas especializadas. 
Haddu, M. y Page, J. (2009). Visual synergies in fiction and documentary film from Latin America. New York: Palgrave Macmillan.

Hennebelle, G. y Gumucio Dagron, A. (1981). Les Cinémas de l'Amérique Latine d'Aujourd'hui. Parías : Lherminier.

King, J. (1993). El carrete mágico: Una historia del cine latinoamericano. Bogotá: TM Editores.

Lillo, G. y Moser, W. (2007). Cine, historia y sociedad: Cine argentino y brasileño desde los años 80. New York: Legas.

León, Ch. (2005). El cine de la margninalidad. Realismo sucio y violencia urbana. Quito: Ediciones Abya-Yala.

Lorenz, Ch. (2005, julio-diciembre). "Historiografía comparada: problemas y perspectivas". Memoria \& Sociedad. Vol. 9, No. 19.

Martin, M. (Ed.) (1997). New Latin American Cinema. Volume one. Theories, practices and transcontinental articulations. Detroit: Wayne State University Press.

(Ed.) (1997), New Latin American Cinema. Volume two. Studies of national cinema. Detroit: Wayne State University Press.

Oroz, S. (1992). Melodrama. El cine de lágrimas de América Latina. Río de Janeiro: Rio Fundo Editora LTDA.

Paranaguá, P. (1984). O Cinema na América Latina. Brasil: L\&PM Editores.

(2000). Le cinéma en Amérique latine. Le miroir éclaté. Historiographie et comparatisme. L'Harmattan: Paris.

- (2003). Tradición y modernidad en el cine de América Latina. Madrid: Fondo de Cultura Económica.

(Ed.). (2003). Cine documental en América Latina. Madrid: Cátedra.

Pérez Llahí, A. (2005). "Los arrabales de la periferia. Albores del sonoro en la cinematografías marginales de América Latina”. En Lusnich, A. (Ed.). Civilización y barbarie en el cine argentino y latinoamericano. Buenos Aires: Biblos.

Pick, Z. (1993). The New Latin American Cinema. A Continental Project. Austin: University of Texas Press.

Rego, C. y Rocha, C. (Eds.). (2011). New Trends in Argentine and Brazilian Cinema. Bristol/Chicago: Intellect.

Sánchez-Biosca, V. (1998, junio). "En torno a algunos problemas de historiografía del cine”. Archivos de la Filmoteca. № 29.

Schumann, P. (1987). Historia del cine latinoamericano. Buenos Aires: Legasa.

Sorlin, P. (1995). Cines europeos, sociedades europeas, 1939-1990. Barcelona: Paidós. 
Tal, T. (2005). Pantallas y revolución: una visión comparativa del Cine de Liberación y el Cinema Novo. Buenos Aires: Lumiere.

Velleggia, S. (2009). La máquina de la mirada. Los movimientos cinematográficos de ruptura y el cine político latinoamericano. Buenos Aires: Altamira. 